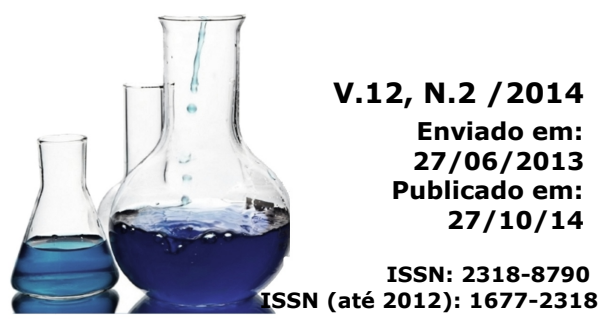

\title{
Escurecimento enzimático: uma aula prática
}

Enzymatic Browning: a practical class

\author{
Maria Teresa Pedrosa Silva Clerici ${ }^{1 *}$, Rodrigo Henrique Sebastião², Larissa Conde Oliveira ${ }^{2}$, Maysa Sales \\ dos Santos², Ana Lúcia Leite Moraes ${ }^{3}$, Sílvia Silveira Clareto ${ }^{3}$ \\ ${ }^{1}$ Docente da Faculdade de Engenharia de Alimento, da Universidade Estadual de Campinas (UNICAMP- \\ $S P)$ \\ ${ }^{2}$ Discente da Universidade Federal de Alfenas (UNIFAL-MG) \\ ${ }^{3}$ Docente da Universidade Federal de Alfenas (UNIFAL-MG) \\ *e.mail: mclerici@fea.unicamp.br
}

\section{Resumo}

Este trabalho apresenta uma aula prática sobre o grupo de enzimas polifenoloxidases, que são responsáveis pelo escurecimento enzimático de frutas e hortaliças. As amostras de vegetais passaram pelo processo de inativação enzimática com o uso de reagentes químicos e pelo método de branqueamento com aplicação de calor (fogão convencional e forno de micro-ondas). Após os tratamentos, a eficiência do processo foi avaliada de forma qualitativa verificando-se a atividade da enzima peroxidase pelo teste com guaiacol e após estocagem sob refrigeração ou congelamento. Os resultados práticos obtidos nesta aula permitem trabalhar conhecimentos multidisciplinares na área de ciência dos alimentos, com aplicações práticas no cotidiano.

Palavras-chave: Polifenoloxidase, Escurecimento enzimático, Branqueamento.

\begin{abstract}
This paper presents a practical class about the enzymes polyphenol oxidases, which have been shown to be responsible for the enzymatic browning of fruits and vegetables. Vegetables samples were submitted to enzymatic inactivation process with chemical reagents, as well as by bleaching methods of applying heat by conventional oven and microwave oven. Process efficiency was assessed qualitatively by both observing the guaiacol peroxidase activity and after the storage period under refrigeration or freezing. The practical results obtained in this class allow exploring multidisciplinary knowledge in food science, with practical applications in everyday life.
\end{abstract}

Keywords: Polyphenol Oxidase, Enzymatic Browning, Bleaching. 


\section{Ficha da atividade desenvolvida}

Título: Escurecimento enzimático: uma aula prática

Público alvo: Alunos dos níveis médio, técnico e superior.

Disciplinas relacionadas: Análise e Tecnologia de Alimentos, Física, Biologia e Química.

\section{Objetivos educacionais:}

$\checkmark$ Promover a interação entre as disciplinas Análise e Tecnologia de Alimentos, Física, Biologia e Química;

$\checkmark$ Abordar os conceitos de pH em alimentos, temperatura de conservação, uso de aditivos químicos, operações de processamento em vegetais;

$\checkmark$ Preparar o vegetal para o processo, através de operações de classificação, higienização e sanitização;

$\checkmark$ Usar alimentos que possuem características ácidas: refrigerante, suco de laranja e vinagre;

$\checkmark$ Usar reagentes químicos e preparar soluções: ácido cítrico, ácido acético e metabissulfito de sódio;

$\checkmark$ Realizar aquecimento utilizando fogão convencional e forno micro-ondas como fontes de calor;

$\checkmark$ Realizar testes para verificar a eficiência dos processos; e

$\checkmark$ Propor novas aplicações práticas.

Justificativa de uso: A realização desta aula prática tem um baixo custo e não utiliza reagentes químicos tóxicos. Nela teremos a possibilidade de adaptação para frutas e hortaliças de diferentes estações do ano e regiões geográficas. Os conhecimentos e os conceitos relacionados para esta aula são multidisciplinares e podem ser aproveitadas para trabalhos de extensão.

\section{Conteúdos trabalhados:}

$\checkmark$ Alimentos: operações de pré-processamento de vegetais

$\checkmark$ Química: Conceitos de alimentos ácidos e preparo de soluções

$\checkmark$ Física: Conceitos sobre transmissão de calor

$\checkmark$ Biologia/Bioquímica: Atividade enzimática e métodos de inativação enzimática 


\section{Introdução}

Fatos como a ação do detergente na louça engordurada, o efeito do cozimento em ovos e o escurecimento de frutas e hortaliças podem ser observados em nossa rotina diária e têm suas explicações embasadas na ciência, principalmente nas áreas de Química, Física e Biologia. Neste sentido a aula prática aparece como instrumento didático adequado e eficiente para proporcionar a aplicação de conceitos existentes em situações cotidianas, visto que essa é uma das questões atuais na prática de ensino de ciências [1].

As aulas práticas são capazes de abranger o conteúdo teórico e possibilitar a interação do aluno com a possibilidade de aplicação dos conceitos aprendidos, tudo isso de maneira mais envolvente e dinâmica. Mas também devem apresentar versatilidade para que possam ser adaptadas e se adequarem as condições disponíveis ao docente, como já abordado nos trabalhos de Galvão [2] e de Oliveira [3], sendo que muitas escolas possuem estruturas e recursos extremamente limitados.

Desta forma o trabalho apresenta e discute a aula prática com os principais conceitos que a envolve, de forma a proporcionar e instigar o pensamento multidisciplinar dos alunos.

A seguir será apresentado o referencial teórico relacionado ao escurecimento enzimático e as principais reações envolvidas, para que o aluno possa estudar previamente o assunto, executar a atividade prática, propor explicações para o que foi vivenciado na aula prática e aplicar estes conhecimentos no cotidiano.

\section{Referencial teórico}

Estima-se que $50 \%$ das frutas tropicais são perdidas devido às reações de escurecimento enzimático. Frutas e hortaliças que possuem enzimas do grupo das polifenoloxidases, enzimas que catalisam as reações de escurecimento enzimático, são totalmente susceptíveis a deterioração quando sofrem danos, cortes e até pelo próprio manuseio do alimento. Estas reações provocam mudanças na cor, textura e sabor em bananas, maçãs, peras, batatas, cogumelos, hortaliças e outros [4].

De acordo com Tomás-Barverán e Espin [5], duas enzimas são relevantes na degradação oxidativa dos compostos fenólicos por causarem a produção de polímeros de coloração marrom (melaninas): a polifenoloxidase (PPO) e a peroxidase (POD). 
Apresenta-se na Figura 1 o esquema da reação de escurecimento enzimático envolvendo a enzima polifenoloxidase (PPO), que é considerada a principal enzima associada com a deterioração dos tecidos vegetais, pois com o rompimento destes por danos mecânicos, esta enzima atua oxidativamente sobre o substrato disponível, acelerando o escurecimento e, consequentemente, a alteração e perda de qualidade do alimento [6].

A peroxidase (POD) é outra enzima presente nos vegetais e tem as seguintes funções:

- proteção dos tecidos vegetais contra os efeitos tóxicos da $\mathrm{H}_{2} \mathrm{O}_{2}$ formada durante o metabolismo celular do vegetal;

- atuação na degradação de ácidos graxos insaturados, através dos radicais livres gerados pela reação enzimática, com formação de compostos voláteis relacionados ao sabor oxidado [7].

A prevenção do escurecimento em vegetais deve ocorrer desde o plantio no campo, colheita, armazenamento e até o processamento, com cuidados ao manusear os vegetais para evitar cortes ou danos mecânicos provocados por quedas. Devem-se evitar também, danos pelo frio, provocados por temperaturas muito baixas (geadas, câmeras frias com temperaturas abaixo da ideal de conservação das frutas), pois estas provocam congelamento parcial da água livre no interior da fruta, formando cristais que danificam os tecidos, favorecendo o escurecimento.

As estratégias de prevenção do escurecimento enzimático durante as operações iniciais de processamento, como o descascamento e corte de frutas e vegetais, são a diminuição do pH (acidificação) do meio, uso de compostos químicos sulfurados e o branqueamento (pré-tratamento com aplicação de calor) [8].

As enzimas, são catalisadores biológicos, possuem um pH ótimo ou uma região de $\mathrm{pH}$ ótimo no qual sua atividade é máxima, e no caso de valores extremos de $\mathrm{pH}$, em geral, podem desnaturar tornando-as inativas [9]. As enzimas PPOs apresentam a faixa de $\mathrm{pH}$ ótimo entre os valores de 5,0 a 7,0; e em condições de pH menores que 3,0, são inativadas [8]. 


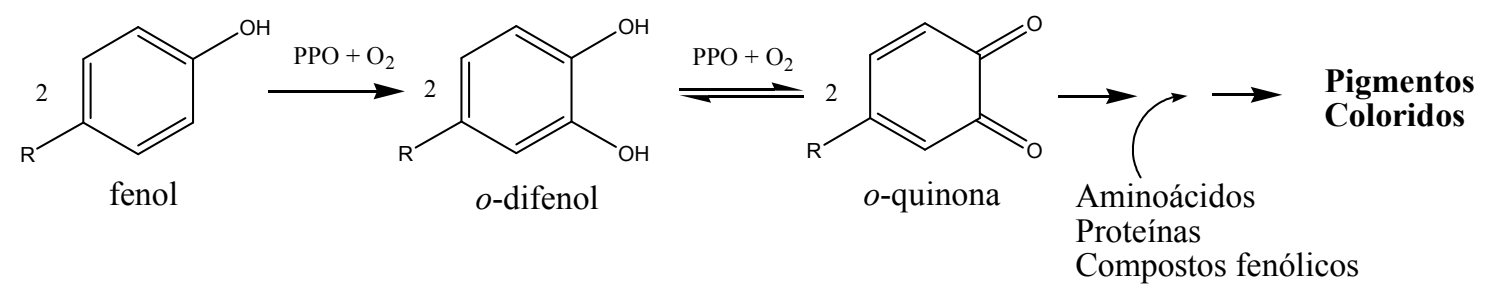

Figura 1. Reações responsáveis pelo escurecimento enzimático de muitos produtos vegetais. Onde: PPO= polifenoloxidase e $\mathrm{R}=$ radical.

Uma das maneiras de retardar o escurecimento enzimático é eliminando o contato do tecido vegetal danificado com o oxigênio, já que a PPO requer oxigênio para iniciar a reação de escurecimento. Procedimentos como a utilização de embalagens impermeáveis, a exclusão do oxigênio por injeção de nitrogênio e a prevenção de danos mecânicos provocados no tecido durante o transporte e armazenamento são úteis na prevenção do escurecimento. Entretanto, isto nem sempre é possível, ocorrendo o escurecimento tão logo o oxigênio seja reincorporado ao alimento. Portanto a maneira mais prática de prevenir o escurecimento enzimático é inativar a PPO, isto pode ser por métodos de adição de reagentes químicos ou tratamento térmico [7].

O uso de reagentes químicos como ácidos e sulfitos são geralmente usados isolados ou em associação, pois enquanto os ácidos diminuem o pH, os sulfitos interagem diretamente com intermediários formados durante a ação enzimática e impedem a reação de formação de pigmento escuro. Por exemplo, os sulfitos podem reagir com quinonas, evitando que sofram reações em cadeia; e podem atuar também como agentes redutores, retornando a quinona para a forma de fenol reduzido. Eles são potentes inibidores das PPOs, geralmente utilizados na forma de bissulfito de sódio e metabissulfito de sódio (na forma de gás ou de solução) são largamente utilizados pela indústria de alimento; embora seja tóxico se usado em níveis elevados [7].

Os ácidos normalmente aplicados em alimentos estão entre aqueles de ocorrência natural: cítrico, fosfórico, málico, ascórbico. Em geral, sua ação é diminuir o pH do tecido, diminuindo assim, a velocidade da reação de escurecimento [8]. O ácido cítrico, em conjunto com o ácido ascórbico ou o sulfito de sódio, é utilizado como inibidor químico do escurecimento enzimático.

Como a PPO não pertence à classe de enzimas termorresistentes, a exposição por curto período de tempo em temperaturas de $70^{\circ} \mathrm{C}$ a $90^{\circ} \mathrm{C}$ (relação tempo/temperatura) é suficiente, na maioria dos casos, para a inativação de suas funções catalíticas. Todavia 
diversos problemas aparecem em função do uso do calor, como exemplo frutas e verduras tornam-se cozidos, o que acarreta em mudanças na textura, na cor e no sabor. A relação tempo/temperatura se torna muito importante para conferir o branqueamento eficiente sem que ocorra grandes alterações sensoriais do alimento; entretanto o processo de aplicação de calor é um fator que depende da quantidade de enzima e do pH do produto [7].

Como é difícil avaliar a atividade da PPO durante o tratamento de branqueamento, tem sido usada a enzima peroxidase (POD) como indicadora. As PODs são enzimas que também estão presentes nos alimentos, sua principal característica é a termoestabilidade $[8,9]$ associada à capacidade de se regenerar após sofrer desnaturação térmica. A regeneração ocorre em poucas horas após o tratamento térmico quando o alimento é mantido em temperatura ambiente, ou mais lentamente sob congelamento; sendo que são capazes de manter atividade em baixas temperaturas e atividade de água. Isso permite que a avaliação da atividade da peroxidase possa ser utilizada como um indicador no monitoramento da eficiência do processo de branqueamento. Para avaliar a atividade da peroxidase, se usa a reação com o guaiacol, cuja reação principal com a POD está apresentada no esquema da Figura 2.

4<smiles>COc1ccccc1O</smiles>

Guaiacol<smiles>COc1ccc2c(c1)Oc1cc(OC)ccc1-c1ccc(OC)cc1Oc1cc(OC)ccc1-2</smiles>

Tetraguaiacoquinona (composto marron escuro)

Figura 2. Reação do guaiacol com a água oxigenada $\left(\mathrm{H}_{2} \mathrm{O}_{2}\right)$ catalisada pela peroxidase (POD) formando um pigmento de coloração escura

\section{Objetivo}

\subsection{Objetivo geral}

Elaborar um roteiro de aula prática para ensino de níveis médio, técnico e superior nas áreas de Biologia, Química, Alimentos (Tecnologia e Ciência de Alimentos, Farmácia, Nutrição, Gastronomia e outros) apresentando e discutindo os processos de inativação 
enzimática de frutas e hortaliças por métodos físicos e químicos.

\subsection{Objetivos específicos}

$\checkmark$ Promover a interação entre as disciplinas de Análise e Tecnologia de Alimentos, Química, Biologia e Física;

$\checkmark$ Abordar os conceitos de pH em alimentos, temperatura de conservação, uso de aditivos químicos, operações de processamento em vegetais;

$\checkmark$ Preparar o vegetal para o processo, por meio das operações de classificação, higienização e sanitização;

$\checkmark$ Usar alimentos que possuem características ácidas: refrigerante, suco de laranja e vinagre;

$\checkmark$ Usar reagentes químicos e preparar soluções: ácido cítrico, ácido acético e metabissulfito de sódio;

$\checkmark$ Realizar aquecimento utilizando fogão convencional e forno micro-ondas como fontes de calor;

$\checkmark$ Realizar testes para verificar a eficiência dos processos; e

$\checkmark$ Propor aplicações novas práticas.

\section{Material e Métodos}

A descrição da metodologia e a discussão dos resultados apresentam algumas legendas que envolvem conhecimentos específicos de Química ( $\neg$ ) e Física ( $\bullet$ ) e os que não estão com legendas se referem aos conhecimentos de Biologia e Bioquímica de Alimentos.

\subsection{Matérias-primas}

$\checkmark$ Maçã

Outros vegetais opcionais: pera, banana, vagem, couve-flor, batata e outras frutas e legumes regionais.

\subsection{Vidraria e utensílios}

$\checkmark$ Béqueres com capacidade de $500 \mathrm{~mL}$ e $250 \mathrm{~mL}$

$\checkmark$ Balão volumétrico de $100 \mathrm{~mL}$

$\checkmark$ Balão volumétrico de $200 \mathrm{~mL}$

$\checkmark$ Peneiras pequenas 
Das enzimas à análise sensorial: relato de aula prática interdisciplinar

$\checkmark$ Pipetas graduada de $1,0 \mathrm{~mL}$

$\checkmark$ Pera de borracha ou pipetador manual para uso na pipeta

$\checkmark$ Bacias de plástico de aproximadamente 2,0 L

$\checkmark$ Panelas de aço inox

$\checkmark$ Etiquetas ou rótulos adesivos

$\checkmark$ Embalagens plásticas transparentes

\subsection{Equipamentos}

$\checkmark$ Fogão

$\checkmark$ Forno micro-ondas

$\checkmark$ Balança

$\checkmark$ Geladeira ou freezer

$\checkmark$ Seladora (opcional)

\subsection{Reagentes}

\subsubsection{Higienização}

Solução de água sanitária, padrão alimentício. Preparada, segundo indicação da ANVISA conforme a Portaria CVS-6/99 de 10/03/99.

Preparo: Adição de $10 \mathrm{~mL}$ (uma colher de sopa rasa) de água sanitária (para uso geral a 2,0 - 2,5\% de concentração de cloro ativo) em um litro de água ou $20 \mathrm{~mL}$ (2 colheres de sopa rasas) de hipoclorito de sódio a $1 \%$ em um litro de água.

\subsubsection{Inativação enzimática (branqueamento)}

$\checkmark$ Ácido cítrico $1 \%$

Pipetar um (1) $\mathrm{mL}$ de ácido cítrico em um balão volumétrico de $100 \mathrm{~mL}$ e completar até o menisco com água destilada, fechar o balão e homogeneizar.

Vinagre de álcool (deve ser límpido e incolor) $(200 \mathrm{~mL})$

Refrigerante (deve ser límpido e incolor, tipo refrigerante de limão) $(200 \mathrm{~mL}$ )

Suco de laranja (exceto laranja-lima), recém-preparado (200 mL)

Solução de metabissulfito de sódio $\left(\mathrm{Na}_{2} \mathrm{~S}_{2} \mathrm{O}_{5}\right)$ 
Pesar, em balança analítica, $31 \mathrm{mg}$ de metabissulfito de sódio, transferir para um béquer e adicionar $50 \mathrm{~mL}$ de água destilada, dissolver com auxílio de um bastão de vidro, transferir para um balão volumétrico de $200 \mathrm{~mL}$, enxaguar o béquer 3 vezes com água destilada (em torno de $20 \mathrm{~mL}$ ), transferindo esta água de lavagem para o balão contendo o metabissulfito, completar o volume do balão com água destilada até o menisco.

\subsubsection{Teste do guaiacol}

$\checkmark$ Guaiacol $1 \%$

$\downarrow$ Pipetar um (1) mL de guaiacol em um balão volumétrico de $100 \mathrm{~mL}$ e completar até o menisco com água destilada, fechar o balão e homogeneizar.

$\mathrm{H}_{2} \mathrm{O}_{2} 10$ volumes.

\section{Procedimentos}

\subsection{Preparo das amostras}

Neste trabalho foram utilizadas maçãs classificadas (sem danos físicos e íntegras), higienizadas por imersão em solução de água sanitária (ver item 3.4.1) por 15 minutos e em seguida lavadas com água potável, conforme a Figura 3.

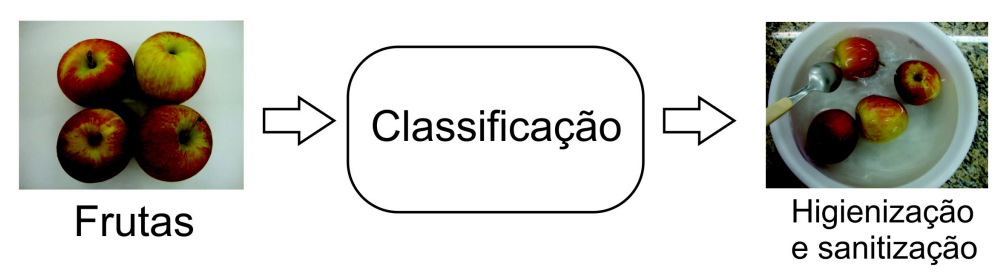

Figura 3. Fluxograma do preparo das maçãs

Depois de higienizadas, as maçãs foram cortadas em quatro partes para que o miolo, contendo as sementes, pudesse ser retirado sem dano e de maneira a não contaminar a polpa com possíveis microrganismos presentes nele. Os pedaços foram fatiados em tamanho aproximado de $0,5 \mathrm{~cm}$ de largura. Foram divididos em 8 porções, onde uma será o controle e as demais submetidas aos tratamentos conforme esquema apresentado na Figura 4. 


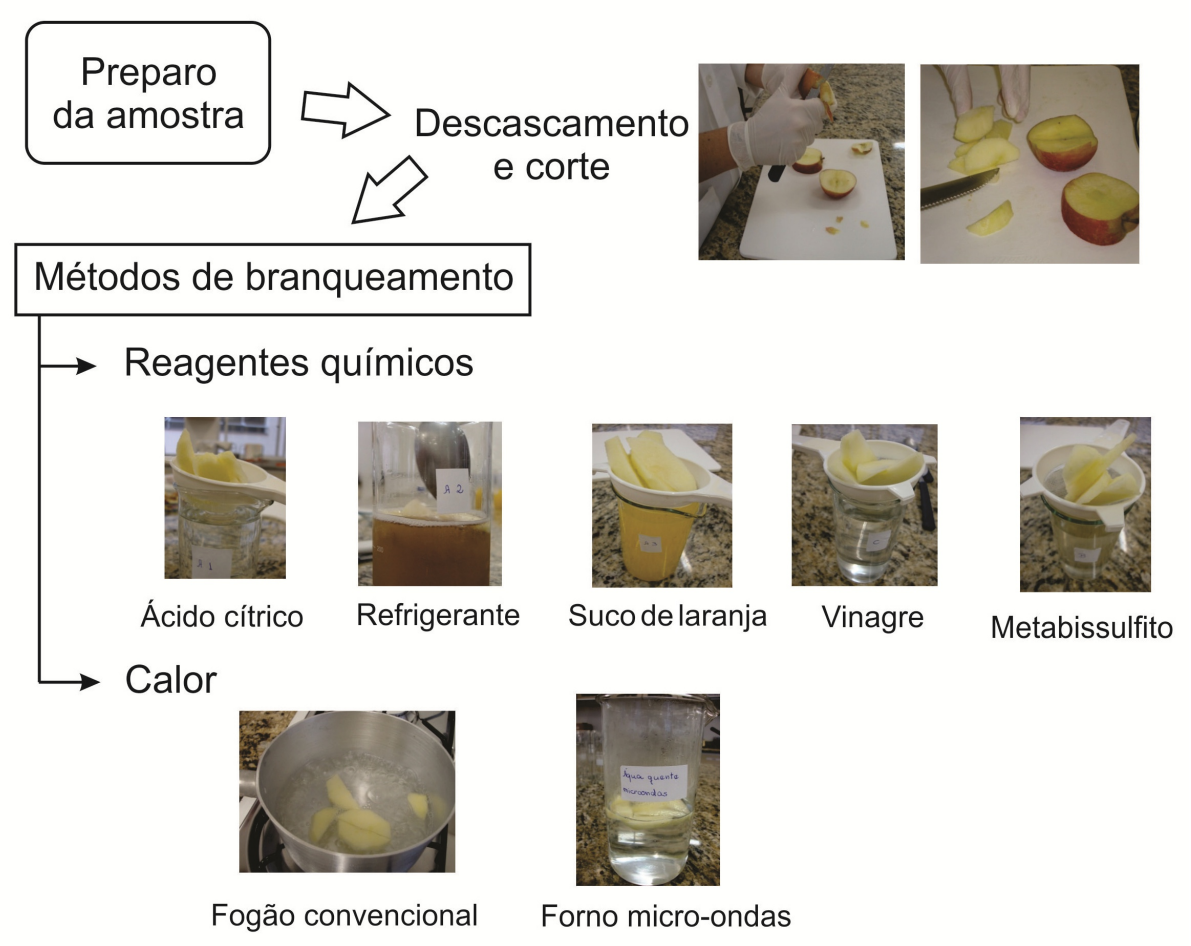

Figura 4. Fluxograma do processo de inativação enzimática das fatias de maçãs com os diferentes tipos de tratamento

\subsection{Controle}

Três fatias da fruta foram separadas e foi realizado o teste do guaiacol após 5, 10 e 15 minutos, para comparação com os demais tratamentos.

Uma porção de maçã foi embalada em embalagem plástica, o ar foi retirado e a embalagem fechada (selamento ou fita adesiva). O produto foi identificado como amostra sem tratamento (CTRL), datado e armazenado no freezer por sete dias. Este grupo foi usado para avaliação comparativa dos resultados.

\subsection{Branqueamento}

\subsubsection{Tratamento com reagentes químicos}

Uma porção da fruta foi colocada, de forma a ficar submersa, em cada uma das soluções dos diferentes reagentes por 5, 10 e 15 minutos (com agitação suave com uma colher), na seguinte sequência:

$\checkmark$ ácido cítrico $1 \%(\mathrm{~A} 1)$

$\checkmark$ refrigerante, que possui ácido fosfórico em sua composição (A2)

$\checkmark$ suco de laranja, que possui ácido cítrico (A3) 
$\checkmark$ vinagre, que possui ácido acético (A4)

$\checkmark$ metabissulfito de sódio (B)

Depois de completado o tempo (5, 10 e 15 minutos), uma fatia de maçã foi retirada para realizar o teste de guaiacol. Após o tempo máximo de 15 minutos, as demais fatias foram retiradas da solução, drenadas por 2 minutos (com auxílio da peneira), separadas em duas porções e colocadas em embalagens plásticas, que foram fechadas com 0 auxílio de uma fita crepe ou com o uso de seladora.

Caso for armazenar em geladeira (armazenar por no máximo 7 dias) ou no freezer (para avaliar após 7 ou 15 dias): identificar cada amostra com o tipo de tratamento, datar e armazenar. Veja modelo na Figura 7.

\subsubsection{Tratamento com aplicação de calor}

a) Uso de fogão convencional

Foram aquecidos $200 \mathrm{~mL}$ de água em fogão a gás, uma porção de fruta foi colocada e mantida em fervura por 2 minutos.

Em seguida, a fruta foi colocada em um banho de gelo e resfriada para evitar o cozimento excessivo. Após resfriamento, a fruta foi colocada em uma peneira e a água foi drenada (aproximadamente 2 minutos). Uma fatia foi retirada e foi realizado o teste do guaiacol (ver item 4.4). As demais fatias de maçã foram colocadas em embalagens plásticas e seladas.

Caso for armazenar: proceder como descrito em 4.3.1

b) Uso do forno micro-ondas

Para o tratamento com calor utilizando o forno micro-ondas, foi aquecida a água (200 mL) em recipiente de vidro (béquer) por 1 minuto em potência médio-baixo e, em seguida, foi acrescentada uma porção de fatias de frutas de maneira que elas ficaram submersas e foram tratadas no micro-ondas por mais 1 minuto na mesma potência. Após este tempo, as fatias foram transferidas para um banho de gelo. As fatias foram retiradas do banho de gelo, drenadas com ajuda da peneira (aproximadamente 2 minutos). Uma fatia foi retirada para realizar o teste do guaiacol (item 4.4). As porções foram embaladas, seladas e rotuladas.

Caso for armazenar: proceder como descrito em 4.3.1 


\subsection{Teste do Guaiacol}

As fatias de maçãs, separadas de cada tratamento e do controle, foram submetidas ao teste do guaiacol:

Numa fatia de maçã, adicionar uma gota de guaiacol $1 \%$ e uma gota de $\mathrm{H}_{2} \mathrm{O}_{2}$ no
mesmo local. Esperar por 2 minutos.

Avaliar o resultado:

Aparecimento de uma coloração marrom avermelhada, indica que a enzima peroxidase não foi inativada;

$\checkmark$ A ausência de coloração marrom avermelhada indica que a enzima peroxidase foi inativada.

\section{Resultados e discussão}

\subsection{Uso de reagentes químicos para evitar o escurecimento enzimático}

A Figura 5 mostra os resultados para os diferentes tratamentos químicos nos tempos de 5, 10 e 15 minutos das fatias submersas nas soluções e do grupo controle. Enquanto as frutas permaneceram submersas nas soluções, elas não escureceram, porém ao serem retiradas da água, foi possível observar que a POD não foi inativada pela ação dos reagentes usados, indicando que os reagentes ácidos e o metabissulfito de sódio impediram o escurecimento por mecanismos de atuação somente na PPO. Como o trabalho foi desenvolvido por alunos, que colocaram as gotas dos reagentes para obtenção da reação de cor do guaiacol com a POD, a Figura 5 apresenta a informação de que todos apresentaram reação positiva ao guaiacol, mas nada se deve afirmar sobre a variação de coloração, pois outros fatores podem estar envolvidos, como tempo que era indicado para drenar a fruta após a retirada da solução e quantidade de reagente utilizado para teste da atuação enzimática, uma vez que foi usado frasco com tampa conta-gotas.

O uso de agentes acidulantes são geralmente utilizados para manter o $\mathrm{pH}$ do meio abaixo do ótimo para a ação catalítica das enzimas em alimentos. Neste caso, foram usados ácidos orgânicos, cítrico e acético, e o inorgânico, o ácido fosfórico, presente no refrigerante.

Os ácidos atuam por dois mecanismos:

agem diretamente na PPO, complexando o cobre do grupo prostético, causando sua inibição; e 
$\checkmark$ reduzem as quinonas a sua forma anterior de fenóis, impedindo a formação dos pigmentos escuros [10].

Por isso, ao longo do tempo de contato, foi notado que as frutas tratadas com ácidos e bissulfitos, mesmo com a POD ativa, apresentaram colorações mais claras que o controle.

Para evitar o escurecimento de vegetais durante o preparo caseiro, pode-se usar suco de laranja e refrigerante para receber as frutas cortadas, ou o uso de gotas de vinagre ou limão na água onde serão colocados os legumes cortados, como batata, cenoura, couveflor. A solução contendo ácido, contribui para manter o $\mathrm{pH}$ ácido e diminuir a oferta de oxigênio no tecido cortado do vegetal.

O metabissulfito de sódio é um reagente redutor que age diretamente na enzima ou nos compostos da reação, formando compostos sulfonatados sem coloração, ou reduzindo-os aos fenóis precursores. Seu uso é industrial e tem que atender as normas da legislação vigente, que estipula a quantidade residual no produto final, conforme os exemplos do limite máximo expresso em $\mathrm{SO}_{2}$ residual: 0,01g/100 $\mathrm{g}$ para frutas dessecadas; $0,02 \mathrm{~g} / 100 \mathrm{~g}$ para legumes e verduras desidratadas e 0,02g/100 $\mathrm{g}$ suco de frutas [11].

O uso de metabissulfito de sódio em alimentos pode causar efeito adverso que pode ser pela ingestão ou inalação. As reações adversas provocadas pelos agentes sulfitantes estão relacionadas principalmente à deficiência da enzima sulfito-oxidase, naturalmente presente nos seres humanos, como bronco-constrição, que é prejudicial para pessoas alérgicas elou portadoras de asma, entretanto seus mecanismos não foram totalmente elucidados [11]. 


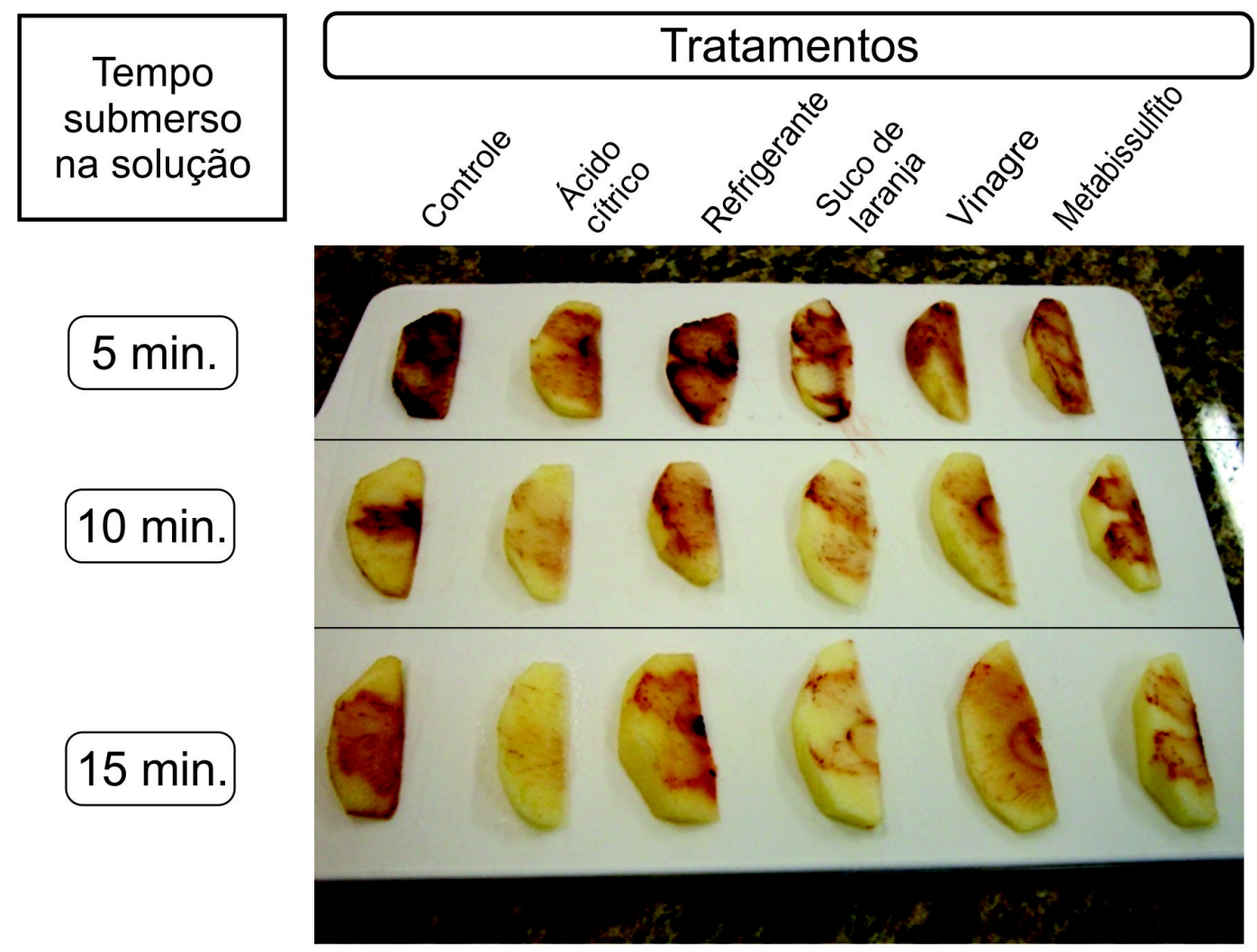

Figura 5. Resultado do teste de guaiacol para as fatias de maçãs que sofreram tratamentos por ação de reagentes químicos.As frutas ficaram mergulhadas na solução correspondente pelo tempo determinado, depois foram retiradas, deixadas em peneira por dois minutos para drenar a solução e em seguida foi realizado o teste do guaiacol.

\subsection{Uso de calor para evitar o escurecimento enzimático}

Na Figura 6 pode-se verificar que o branqueamento pelo método da aplicação de calor, tanto pelo aquecimento convencional em água quente no fogão, quanto pelo microondas, desnaturou a enzima peroxidase, indicando que os processos tiveram a combinação de tempo e temperatura adequados para evitar o escurecimento enzimático. Ressalta-se que o tempo com o uso de forno de micro-ondas foi menor que no aquecimento convencional.

No aquecimento convencional, onde pedaços de frutas são colocados em água quente, com contínuo aquecimento, a transferência de calor é dada pelos movimentos de condução e convecção, que atuam concomitantemente sobre o produto, pois por meio da água ocorre a movimentação do produto e nas fatias do alimento, a penetração do calor acontece da camada mais externa para mais interna [12].

No aquecimento do produto por uso de forno de micro-ondas, as micro-ondas emitidas são radiações eletromagnéticas cuja frequência está na faixa de 3 a $300000 \mathrm{mHz}$ 
e se convertem em calor ao serem absorvidas pela matéria. Nos alimentos, distinguem-se fundamentalmente por condução iônica e por rotação de dipolos. A condução iônica se deve ao deslocamento de íons que são capazes de colidir e transmitir energia cinética para as moléculas vizinhas, aumentando seu movimento e, finalmente, gerando calor. A rotação de dipolos acontece pela geração de choques e fricção molecular que, assim como no caso anterior, incrementam a energia cinética e a temperatura [13].

O binômio tempo e temperatura de tratamento térmico dos vegetais pode variar de acordo com a fonte de calor utilizada, tipo de vegetal, tipo de corte e espessura. As temperaturas utilizadas no tratamento térmico podem variar de 70 a $100^{\circ} \mathrm{C}$ por diferentes tempos, e, durante estudos prévios de eficiência de branqueamento, o teste do guaiacol pode ser utilizado (retirando fatias ou pedaços de vegetais e fazendo o teste, para melhor visualização), para se chegar a melhor combinação destes parâmetros.

O tratamento térmico provoca mudanças na textura e sabor do produto, portanto é mais usado para produtos que serão cozidos antes do consumo, como legumes congelados e pouco usado para frutas, que serão consumidas na forma crua.

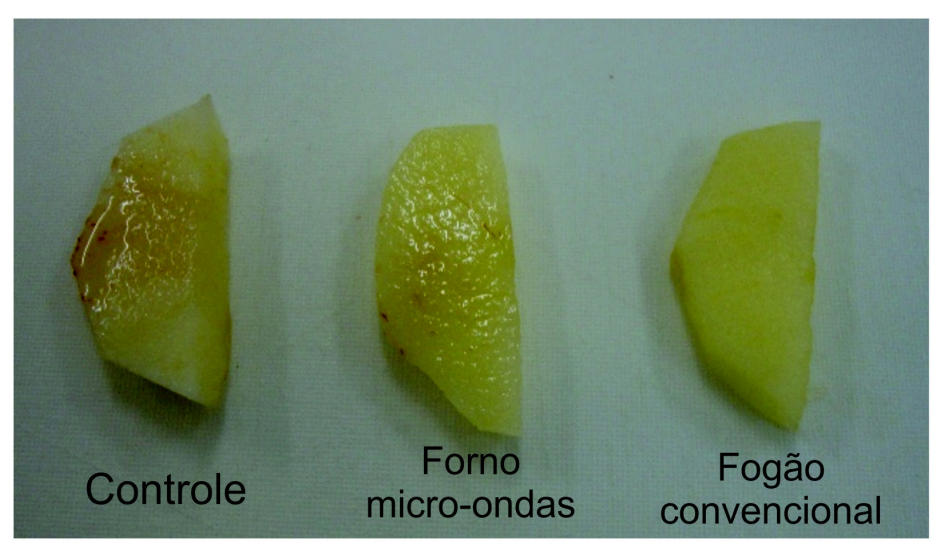

Figura 6. Resultado do teste de guaiacol para as maçãs que receberam aplicação de calor para o branqueamento em forno micro-ondas e fogão convencional. A fruta controle apresentou reação positiva ao teste, enquanto as demais que foram mergulhadas em água quente e mantidas aquecidas pelo tempo necessário para inativação enzimática apresentaram teste negativo, indicativo de sucesso na desnaturação da peroxidase.

Após o tratamento com reagentes químicos e com o uso do calor, os produtos foram armazenados sob refrigeração ou congelamento por períodos que podem variar de 7 a 21 dias.

O congelamento é uma forma de conservação de alimentos em que a água transforma-se em gelo, diminuindo a atividade de água no alimento, e a temperatura baixa 
é responsável por diminuir a energia de ativação das enzimas, de maneira que elas não são capazes de catalisar a reação. No congelamento realizado de forma lenta o efeito do escurecimento será mais rápido, pois a formação de cristais de gelo pode perfurar os tecidos. Segundo Reis [8], as células de plantas intactas não escurecem por via enzimática porque os fenóis e as PPO estão em diferentes compartimentos da célula vegetal. Já no congelamento rápido, normalmente utilizado pelas indústrias, não ocorre a formação de cristais de gelo de dimensões que são capazes de influenciar na célula.

$\mathrm{Na}$ Figura 7, que mostra as fatias de maçãs tratadas com reagentes químicos e congeladas por 7 dias, pode-se verificar que houve reações de escurecimento ocorridas nas amostras controle (CTRL), com ácido cítrico (A1) e com vinagre (A4), já nas demais amostras o escurecimento ainda não se manifestou. Cabe ressaltar que após tempo prolongado de congelamento (acima de 15 dias) todas as frutas vão apresentar o escurecimento, pois os grandes cristais de gelo vão danificar as frutas e fazer com que haja interação do substrato com a enzima, na presença do oxigênio dissolvido nas células vegetais.

Na Figura 8 se apresentam as fatias de maçã que foram tratadas termicamente por forno convencional e por micro-ondas, verificou-se que o armazenamento durante os sete dias de congelamento não mostrou escurecimento enzimático. Este resultado era esperado, pois este processo é usado para desnaturação irreversível de enzimas.

Desta forma, pode-se verificar que o congelamento não inativa as enzimas do escurecimento e para que as frutas e legumes permaneçam com a coloração típica, as indústrias costumam usar métodos combinados de calor e uso de ácidos ou matabissulfitos, para diminuir o tempo de tratamento térmico e evitar grandes perdas de textura, sabor e cor. 


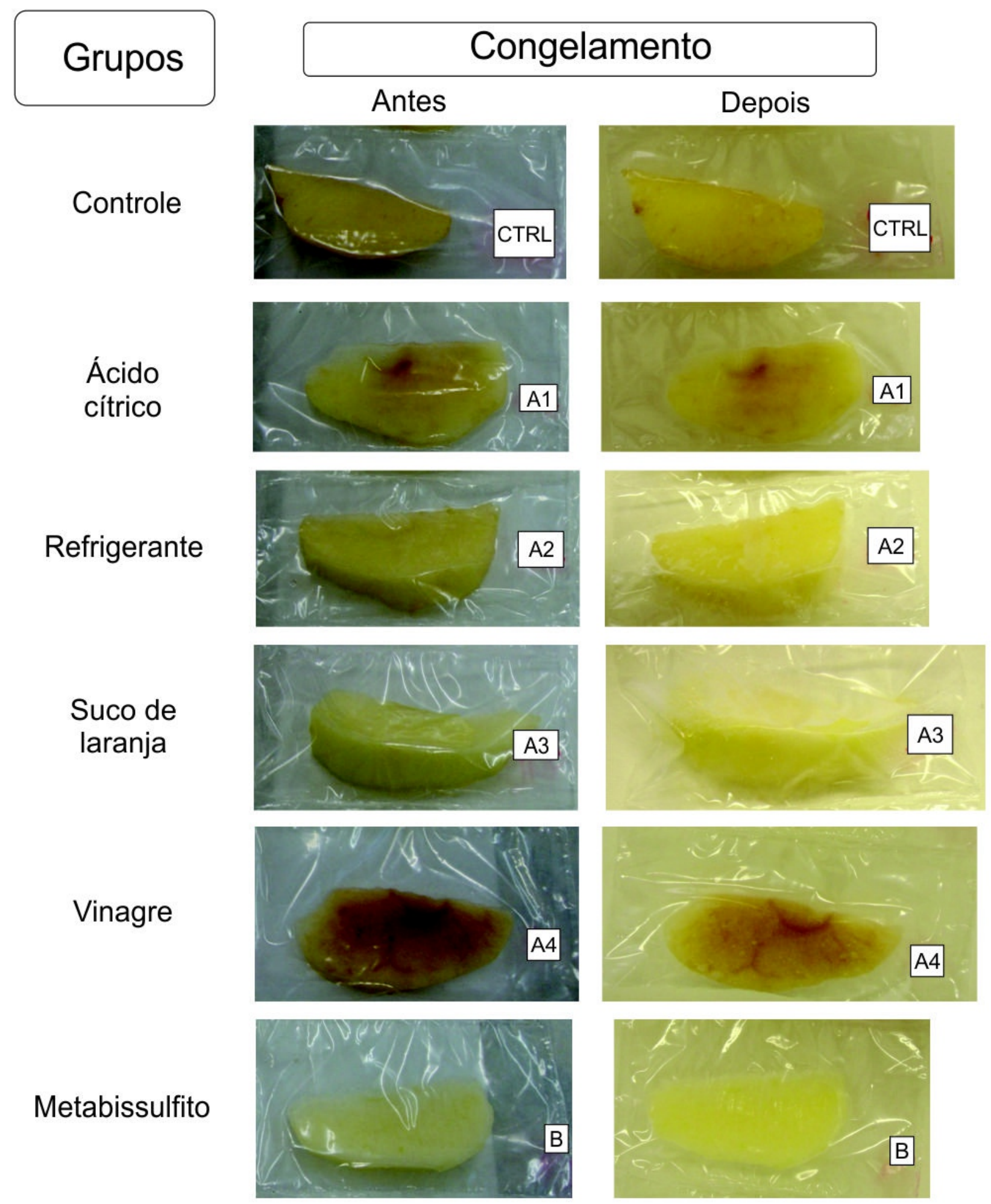

Figura 7. Maçãs embaladas em sacos plásticos no primeiro dia de tratamento com reagentes (antes) e após sete dias de congelamento lento $\mathrm{a}-18^{\circ} \mathrm{C}$ por 7 dias (depois). $\mathrm{O}$ controle não teve tratamento com reagentes. 


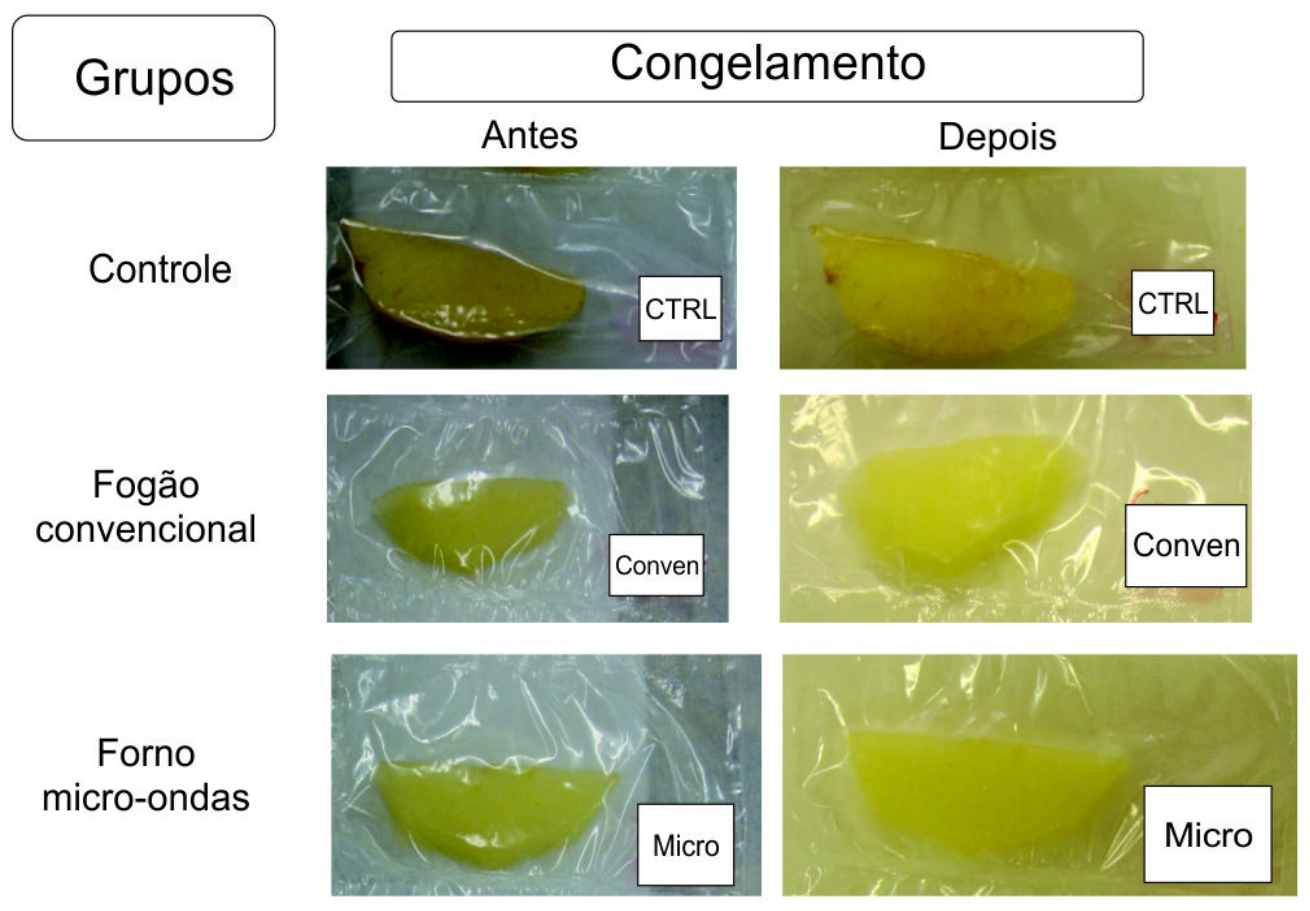

Figura 8. Maçãs embaladas em sacos plásticos no primeiro dia de tratamento com calor (antes) e após sete dias de congelamento lento a $-18^{\circ} \mathrm{C}$ por 7 dias (depois). $\mathrm{O}$ controle não teve nenhum tratamento térmico.

\section{Conclusão}

Pode-se, através desta aula, verificar que as enzimas que promovem o escurecimento em presença de oxigênio e compostos fenólicos são de grande importância para o processamento de produtos vegetais, principalmente frutas, legumes e verduras, pois podem gerar compostos escuros que mudam a cor e o sabor destes, diminuindo a aceitação sensorial. Portanto, aprender alguns processos simples de inativação enzimática poderá contribuir para diminuir a perda de alimentos durante o preparo e consumo.

Como aula interdisciplinar, foi possível revisar conceitos práticos de Bioquímica, em relação à presença de enzimas em tecidos vegetais, atividade ótima e desnaturação; de Química, em relação à acidez e pH de soluções e técnicas fáceis de preparo de soluções, em relação à Física, sobre os processos de transferência de calor, e à Ciência e Tecnologia de Alimentos, os conceitos de higiene de vegetais, classificação, seleção, processos e embalagem.

Todas as fotos presentes neste trabalho foram resultados de aulas práticas, onde os alunos participaram ativamente deste processo e a avaliação desta aula foi realizada com questões subjetivas em provas, onde foi solicitado aos alunos que propusessem 
métodos possíveis de manter uma mandioca descascada crua para venda em feiras.

\section{Propostas de trabalhos}

\subsection{Prática de branqueamento}

Possibilidade de uso do processo de inibição da atividade enzimática de polifenoloxidases de diversas frutas e vegetais de colorações claras ou esverdeadas em aulas experimentais, como mostrado na Figura 9.
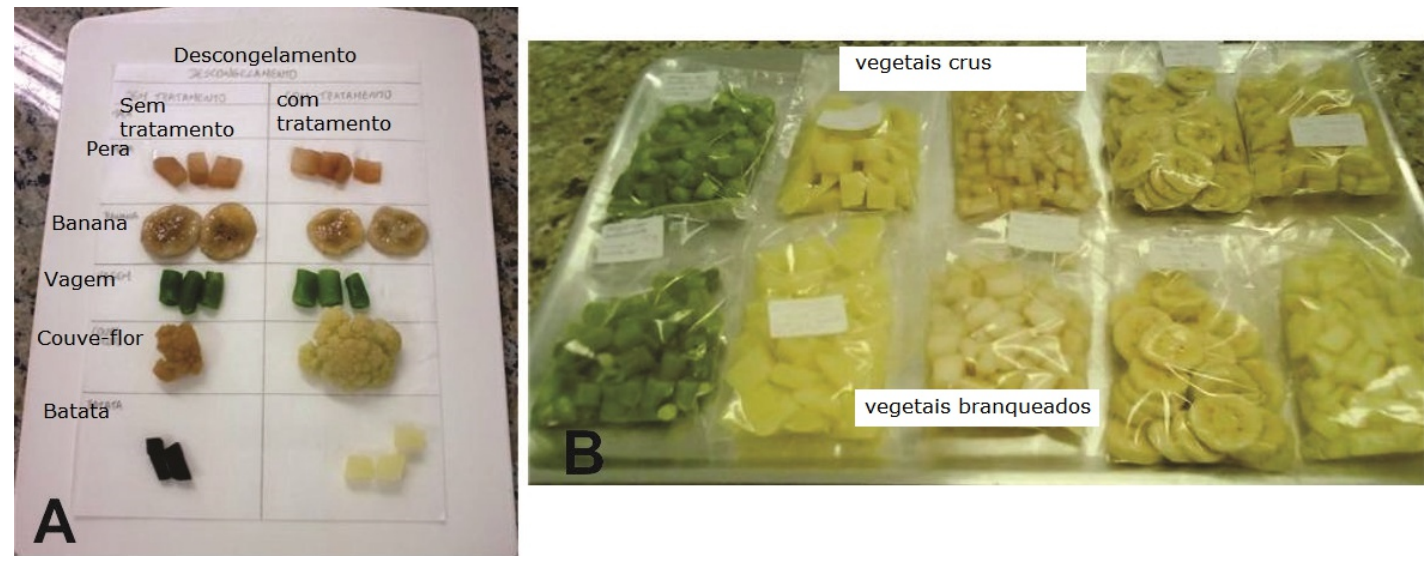

Figura 9. A: Aula prática de uso de ácidos e do calor para evitar o escurecimento enzimático de diversos alimentos; de cima para baixo: pera e banana (ácidos), vagem, couve flor e batata (tratamento térmico). B: Vegetais crus e branqueados pelo calor

\subsection{Salada de frutas}

Preparar uma salada de frutas adicionando inicialmente o suco de laranja ou refrigerante, assim esses ingredientes serão capazes de minimizar o escurecimento enzimático das frutas contidas na salada.

\section{Aplicações práticas no dia-a-dia}

Mostrar a relação entre os resultados da prática com os conceitos teóricos de forma que possam ser visualizadas as aplicações no cotidiano, como por exemplo:

$\checkmark$ evitar amassar e apertar frutas em exposição em feiras e supermercados;

$\checkmark$ evitar usar as unhas para verificar a qualidade de frutas e hortaliças (exemplo, na compra de quiabos, melancias e melões);

$\checkmark$ não deixar as frutas caírem ou empilhadas de forma que muito peso se acumule sobre elas; e 
usar corretamente os compartimentos da geladeira, ou seja, colocar as frutas e verduras nas gavetas apropriadas, para evitar o dano pelo frio.

\section{Referências}

[1] Marandino M. A prática de ensino nas licenciaturas e a pesquisa em ensino de ciências: questões atuais. Cad Bras Ens Fís 2003; 20 (2): 168-193.

[2] Galvão TB, Ferreira DANM, Carvalho LEF, Rezende NCC, Voigt EL. Protocolo acessível para aula prática sobre fatores físicos e químicos que afetam a integridade das biomembranas. RBEBBM [periódicos na internet]. 2012. Acesso em 2 de outubro de 2013. Disponível em: http://bioquimica.org.br/revista/ojs/index.php/REB/article/view/168.

[3] Oliveira RV, Takatsuka JP, Bonfin VL, Paula Rogério A, Pelli A, Peixoto PG Construção de fonte e cuba de eletroforese horizontal e sua aplicação em aulas práticas de bioquímica. RBEBBM [periódicos na internet]. 2012. Acesso em 2 de outubro de 2013. Disponível em: http://bioquimica.org.br/revista/ojs/index.php/REB/article/view/170/158.

[4] Damodaran S, Parkin KL, Fennema OR. Química de alimentos de Fennema, 4 ed., Ed. Porto Alegre: Artmed; 2010.

[5] Tomás-Barberán FA, Espin JC. Phenolic compounds and related enzymes as determinants of quality in fruits and vegetables. J Sci Food and Agricult 2001; 81 (9): 853876.

[6] Fennema DR (Ed.) Principles of food science pt.1.Food chemistry. ed. Marcel Dekker; 1976. Chapter 4, Enzyme, p. 285-345,.

[7] Araújo JMA. Química de Alimentos, Teoria e Prática, 3ed. Ed. Viçosa: Universidade Federal de Viçosa; 2004.

[8] Reis FR. Efeito dos processos de branqueamento e acidificação sobre a cor e a absorção de gorduras de batatas-palha. Dissertação de Mestrado [Tecnologia de Alimentos], Universidade Federal do Paraná. 2007.

[9] Nelson DL, Cox MM. Princípios de Bioquímica de Lehninger, 5ed, ed. Porto Alegre: Sarvier: Artmed; 2009.

[10] Sapers GM, Miller RL. Browning Inhibition in Fresh-Cut Pears. J. Food Science 1998; 63 (2): 342-346.

[11] Favero DM, Ribeiro CSG, Aquino AD. Sulfitos: importância na indústria alimentícia e seus possíveis malefícios à população. Segurança Alimentar e Nutricinal 2011; 18 (1): 11 20.

[12] Baruffaldi R, Oliveira MN. Fundamentos de Tecnologia de Alimentos, ed. São Paulo: Atheneu; 1998.

[13] Ordoñez JA, Rodríguez M, Alvarez L, Sanz M, Minguillón G, Perales L, Cortecero M. Tecnologia de alimentos: componentes dos alimentos e processos. ed. Porto Alegre Artmed; 2005. 